\title{
Protocolo de uso de los colutorios antisépticos
}

Santos, Antonio

Enrile, Francisco

Casals, Elas

Serrano, Jorge

Fombellida, Fernando

Calsina, Gloria

Carrasquer, Assumpta

Lorca, Amparo

Pascual, Andrés

Savoini, Marzia
El mantenimiento de un adecuado nivel de higiene oral diario es esencial para la prevención y control de las enfermedades orales asociadas a la placa. Las enfermedades periodontales se han identificado en las primeras civilizaciones pero parece que poco ha cambiado en dos milenios. Las enfermedades periodontales y la caries son todavía dos de las enfermedades más prevalentes en el ser humano.

El papel de la placa bacteriana en la etiología de la gingivitis y de la periodontitis es bien conocido y aceptado. Tanto desde un punto de vista clínico como patológico, la gingivitis es reversible toda vez que se elimine la placa bacteriana que se encuentre alrededor de los dientes. Este hecho quedó claramente demostrado en el estudio de gingivitis experimental de Löe ${ }^{1}$ donde se exponía como el depósito de placa siempre va seguido de inflamación gingival y, como por el contrario la eliminación de la placa controla el proceso.

Los métodos mecánicos de eliminación de la placa dental han existido desde hace milenios. Aproximadamente hace un siglo, la Asociación Dental Americana (ADA) recomendó el régimen mecánico de higiene oral consistente en dos cepillados y una higiene interdental al día. Hasta la fecha, este régimen de higiene oral ha demostrado ser altamente efectivo en ayudar a controlar la caries y las enfermedades periodontales.

Este régimen ha sido el pilar de las recomendaciones de higiene oral dado por los profesionales dentales a los pacientes durante décadas. Esto ha contribuido, sin lugar a dudas, a una mejor higiene de los mismos. Sin embargo, existen pocos estudios a largo plazo apoyando esta recomendación ${ }^{2-4}$. Por diversas razones, este régimen mecánico de higiene oral no suele ser suficiente en la mayoría de la población para mantener la salud oral, como demuestra la alta prevalencia e incidencia de patologías orales.

Dichas patologías siguen siendo de gran preocupación no sólo para los profesionales de la salud oral sino también para los pacientes. Como ha señalado la OMS recientemente, las enfermedades orales, en particular la caries y las enfermedades periodontales, constituyen un problema de salud de alcance mundial que afecta a los países industrializados y cada vez con más frecuencia a los países en desarrollo, en especial, entre las comunidades socialmente deprimidas.

Los datos demuestran que para la mayoría de pacientes las medidas de higiene oral cotidianas, incluido el uso de dispositivos de higiene interdental, como el hilo de seda y los palillos dentales, no controlan de forma efectiva la placa debido principalmente a los problemas en el cumplimiento.

Las limitaciones que presentan estas prácticas de higiene oral sugieren la necesidad de búsqueda y aplicación urgente de otras estrategias. Los métodos mecánicos utilizados en casa han sido considerados desde siempre como la mejor manera de que los pacientes eliminen la placa. 
Incluso, pacientes bien entrenados tienen dificultades en eliminar la placa de zonas de difícil acceso y en particular en zonas posteriores. Además, los pacientes de más edad, aquellos con limitaciones físicas o psíquicas, dientes mal colocados, puentes o aparatos de ortodoncia, etc., pueden encontrar dificultades a la hora de utilizar correctamente el cepillo y los instrumentos de higiene interdental5,6.

Por estas razones, los agentes quimioterapéuticos pueden desempeñar una función clave como coadyuvantes de los métodos mecánicos para la prevención y tratamiento de la enfermedad periodontal7.8.

Aproximadamente hace tres décadas, los investigadores y clínicos sugirieron que el añadir agentes quimioterapeúticos al régimen mecánico podía ayudar en el control de la placa y de la gingivitis ${ }^{9010}$. Las recomendaciones de los profesionales de la salud oral deben estar basados en una evidencia científica clínicamente relevante.

Los agentes quimioterapeúticos en forma de colutorios antisépticos están ganando popularidad y ya se ha publicado un gran número de estudios y datos sobre su seguridad y eficacia. Por tanto, parece claro que los profesionales de la odontología deben recomendar medidas adicionales de higiene oral en base a las necesidades de sus pacientes. No obstante faltan estudios a largo plazo sobre el cumplimiento de los pacientes en el uso de colutorios antisépticos.

Los principales usos de los colutorios bucales son:

A. Para reemplazar los métodos mecánicos de higiene oral (cepillado y hilo de seda) cuando no es posible realizarlos:

Podemos resumir el uso de los colutorios con el siguiente protocolo

1. colutorios terapéuticos

(en pacientes con gingivitis y periodontitis, halitosis,..) administrarlos junto con el tratamiento mecánico

2. colutorios preventivos

2.1 prevención secundaria (en pacientes con enfermedad periodontal tratada , para evitar recidivas)

2.2 prevención primaria (en base a la revisión realizada por la alta incidencia y prevalencia de enfermedad periodontal y al uso insuficiente e inadecuado de los métodos mecánicos de higiene oral parece recomendable su utilización)

2.3 tratamiento de recidivas (como complemento a otras terapias)

- después de la cirugía oral o cirugía periodontal y durante el periodo de cicatrización

- después de la fijación intermaxilar utilizada para tratar fracturas de los maxilares o tras la cirugía ortognática o cosmética-estética de los maxilares

- en infecciones mucosas o gingivales orales agudas cuando el dolor impide la higiene oral mecánica.

B. Como coadyuvante de la higiene oral mecánica

- después del raspado y alisado radicular

- cuando la higiene oral mecánica es inadecuada y persiste la inflamación gingival

- en pacientes médicamente comprometidos

- en pacientes con halitosis

- en pacientes con ortodoncia con mal control de placa y tendencia a la inflamación e hiperplasia gingival

- en la prevención de la caries dental (antisépticos con flúor)

- para disminuir la carga bacteriana de los aerosoles y las bacteriemias generadas por diversas intervenciones orales como el uso de ultra- sonidos, con lo cual disminuimos el riesgo de infecciones cruzadas

- en pacientes con agrandamientos gingivales por etiología farmacológica

- en pacientes con xerostomía para reducir las infecciones oportunistas

- durante el tratamiento de pacientes con enfermedad periodontal activa

- en pacientes con enfermedad periodontal tratada en mantenimiento que no tengan una higiene oral correcta

- en pacientes con grandes rehabilitaciones protésicas y/o implantológicas

- para pacientes disminuidos psíquica o físicamente y que son incapaces de realizar un buen control de placa.

Basados en la revisión de la literatura y en los estudios epidemiológicos sobre la incidencia y prevalencia de las enfermedades periodontales y el uso insuficiente e inadecuado de las técnicas mecánicas de higiene oral (especialmente a nivel interproximal) parece recomendable el uso de colutorios con evidencia científica. 


\section{Bibliografia recomendada}

Para profundizar en la lectura de este tema, el/los autor/es considera/an interesantes los artículos que aparecen señalados del siguiente modo: *de interés **de especial interés.

1. Löe H, Theilade E, Jensen SB. Experimental gingivitis in man. Periodontol 1965;36:177-8

2. Lang NP, Cumming BR, Löe H. Toothbrushing frecuency as it relates to plaque development and gingival health. Periodontol 1973;44:396-405.

3. Hansen F, Gjermo P. The plaque removal effect of four tooth brushing methods. Scandinavian Journal of Dental Research 1971;79:502-6

4. Frandsen A. Mechanical oral hygiene practices. In: Löe H, Kleinman DV. Dental plaque control measures and oral hygiene practices. Oxford- Washington, D.C.: IRL Press, 1986:93-116.

5. Ciancio SG. Use of mouthrinses for professional indications. J Clin Periodontol 1988; 15:520-3

6. Baker K. Mouthrinses in the prevention and treatment of periodontal disease. Current Opinion Periodontol 1993;1:89-96

7. Wolff LF. Chemotherapeutic agents in the prevention and treatment of periodontal disease. Northwest Dent 1985;64:15-24.
8. Bouwsma OJ. The status, future, and problems of oral antiseptics. Current Opinion Periodontol 1996;3:78-84

9. Lang NP, Hozt P, Graf H, Geering AH, Saxer UP, Sturzenberger OP, Meckel AH. Effects of supervised clorhexidine mouthrinses in children. A longitudinal clinical trial. J Periodontal Res 1976;17:101-1.

10. Löe H, Schiott CR, Karring G, Harring T. Two years oral use of clorhexidine in man. I. General design and clinical effects. J Periodontal Res 1976;17:135-44. 